\title{
Sepsis-Induced Potentiation of Peritoneal Macrophage Migration Is Mitigated by Programmed Cell Death Receptor-1 Gene Deficiency
}

\author{
Alfred Ayala ${ }^{a} \quad G^{2}$ endolyn F. Elphick ${ }^{a, c}$ Ye Sul Kim ${ }^{a}$ Xin Huang ${ }^{a}$ \\ Arnaldo Carreira-Rosario ${ }^{a}$ Sadella C. Santos ${ }^{a}$ Nicholas J. Shubin $^{a}$ b Yaping Chen ${ }^{a}$ \\ Jonathan Reichner ${ }^{a} \quad$ Chun-Shiang Chung ${ }^{a}$ \\ ${ }^{a}$ Department of Surgery, Division of Surgical Research, the Alpert School of Medicine at Brown University/Rhode Island

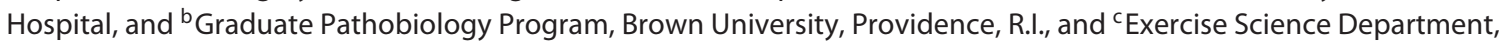 \\ Skidmore College, Saratoga Springs, N.Y., USA
}

\section{Key Words}

Macrophages · Sepsis · Co-inhibitory molecule ·

Signal transduction · Migration · Phagocytosis

\begin{abstract}
The effect of programmed cell death receptor-1 (PD-1) on phagocyte function has not been extensively described. Here we report that experimental mouse sepsis, cecal ligation and puncture (CLP), induced a marked increase in peritoneal macrophage random migration, motility and cell spread, but these changes were lost in the absence of PD-1. Alternatively, phagocytic activity was inversely affected. In vitro cell culture imaging studies, with the macrophage cell line J774, documented that blocking PD-1 with antibody led to aggregation of the cytoskeletal proteins $\mathrm{a}$-actinin and Factin. Further experiments looking at ex vivo peritoneal macrophages from mice illustrated that a similar pattern of a-actinin and F-actin was evident on cells from wild-type CLP mice but not PD-1-/-CLP mouse cells. We also observed that fMLP-induced migration by $\mathrm{J774}$ cells was markedly attenuated using PD-1 blocking antibodies, a nonselective phosphatase inhibitor and a selective Ras-related protein 1 inhibitor. Finally, peritoneal macrophages derived from CLP as opposed to Sham mice demonstrated aspects of both cell
\end{abstract}

surface co-localization with CD11b and internalization of PD-1 within vacuoles independent of CD11b staining. Together, we believe the data support a role for PD-1 in mediating aspects of innate macrophage immune dysfunction during sepsis, heretofore unappreciated.

(C) 2013 S. Karger AG, Basel

\section{Introduction}

Sepsis is the tenth most common cause of death in the USA and the number one cause of death in critically ill patients [1]. This occurs despite the provision of seemingly adequate fluid resuscitation, specific antibiotics, aggressive operative intervention, nutritional support, antibodies to endotoxin/lipid-A/MD2-TLR4 as well as various anti-cytokine therapies $[2,3]$. Thus, it is readily apparent that more knowledge of the pathophysiology of sepsis is needed to develop more effective therapies to control its lethal effects.

From a pathological perspective sepsis is thought to result from a state of disturbed inflammatory homeostasis that is often initiated by infection $[4,5]$. Experimental animals as well as patients often exhibit aspects of a systemic pro-inflammatory state, which is either followed by or of-

\section{KARGER}

E-Mail karger@karger.com

www.karger.com/jin
(C) 2013 S. Karger AG, Basel

1662-811X/13/0063-0325\$38.00/0
Prof. Alfred Ayala

Division of Surgical Research

Aldrich 227, Rhode Island Hospital

593 Eddy Street, Providence, RI 02903 (USA)

E-Mail aayala@ lifespan.org 
ten seen concomitantly with aspects of a generalized immune suppressive or anergic state [6-8]. In this respect, the murine protocol of cecal ligation and puncture (CLP) is the most accepted model for sepsis studies $[9,10]$ as it produces significant aspects of both states of host responsiveness, as well as concomitant infection in the presence of tissue injury. For this reason, many laboratories, including our own, have applied the CLP model to study the role of the anti-inflammatory and/or immune suppressive processes and their contribution to the pathology of sepsis.

The innate immune response is the initial primary defense mechanism typically activated against the pathogen(s) as a part of the initial host response in sepsis $[7,11]$. Macrophages play a central role in the initiation and regulation of this process because they are one of the principal pathogen scavengers and primary producers of inflammatory cytokines [12-14]. In so doing, they not only serve as a member of the first line of defense against microbial pathogens, but also act as a bridge between activation of the innate and adaptive response to foreign agents [12]. Notably, sepsis studies show that macrophages are important contributors to the pro-inflammatory/innate immune response (systemic inflammatory response syndrome, SIRS) [15, 16], and they show marked evidence of dysfunction, immune suppression and reprogramming of key processes associated with pathogen phagocytosis and pro-inflammatory cytokine productive capacity $[15,16]$, along with the ability to present and process microbial antigen(s) for presentation to $\mathrm{T}$ cells [16-18]. In this regard, we have recently demonstrated that the negative immunoregulatory cell surface receptor, programmed cell death receptor-1 (PD-1; CD279), is markedly upregulated on blood monocytes and peritoneal macrophages during sepsis [19]. Furthermore, when peritoneal macrophages were isolated from septic PD-1 gene-deficient $(-/-)$ mice, they demonstrated improved bacterial handling/clearance and improved phagocytic capacity ex vivo when compared to cells derived from septic wild-type (WT) mice, and these PD-1-/- mice had decreased mortality from sepsis. These changes in cellular expression and the effects on phagocytic function in macrophages are independent of the observed changes in the expression of PD-1 and its function on T cells.

As mentioned above, a competent migratory and motility function of macrophages is a crucial process in mediating the movement of phagocytes to the site or source of infection or inflammation so they can contribute to the developing innate response. However, recent studies suggest cells that are stimulated or potentiated to migrate randomly at a greater rate, in turn, spend less time in- volved in the process of forming an immune synapse with $\mathrm{T}$ lymphocytes (the latter process is needed to optimize antigen presentation). Several studies looking at co-inhibitory receptors, such as cytotoxic T lymphocyte-associated antigen-4 (CTLA-4) [20] have suggested that members of this family, which are related to PD-1 [21], may have an impact on the motility and migratory capacity of T lymphocytes. Furthermore, such effects on lymphocyte migration and motility may involve not only classical immune-receptor tyrosine inhibitory motif (ITIM) recruitment and activation of the phosphatases SHP-1/2 [21], but signaling through Ras-related protein 1 (RAP1) also affects cell adhesion molecules such as integrins [22]. However, the contribution of such co-inhibitors to direct or indirect regulation of phagocyte functions, such as phagocytosis and migration, as well as how their actions might be mediated in monocytes and macrophages, are not well understood. In light of our recent observation that septic mouse and human monocytes and macrophages rapidly exhibit increased expression of the co-inhibitory cell surface protein PD-1 [19], and for the reasons just mentioned, we attempted to determine whether PD-1 expression had an effect on the migration and motile capacity of macrophages after septic insult.

\section{Materials and Methods}

\section{Cecal Ligation and Puncture}

As previously described male 8- to 10 -week-old C57BL/6J mice or PD-1-/- mice [23] (kindly provide by Tasuku Honjo, Kyoto University, Kyoto, Japan, via Megan Sykes at the Massachusetts General Hospital, Charlestown, Mass., USA) were anesthetized with isoflurane and, following a midline incision, the cecum was exposed, ligated and punctured twice [24]. Then, the cecum was returned to the peritoneal cavity and the abdominal incision was closed. In the control animals (Sham) the cecum was located and exposed but was neither ligated nor punctured. All of the experiments performed here were carried out in accordance with the National Institutes of Health Guidelines on Laboratory Animals [25] and were approved by the Lifespan-Rhode Island Hospital Committee on Animal Use and Care.

\section{Flow Cytometry}

Cultured murine-derived J774 cells (as described by ATCC) or mouse peritoneal leukocytes were isolated; the leukocytes were stained with either anti-F4/80 (clone BM8, rat IgG2a), anti-PD-1 (clone J43, hamster IgG2), anti-PD-L1 [B7-H1] (clone M1H5, rat IgG2a) or anti-CD11b (clone M1/70, rat IgG2b) antibodies, along with the appropriate hamster/rat isotype controls (eBioscience, San Diego, Calif., USA), and analyzed via flow cytometry on a FACSArray flow cytometer (BD Biosciences; San Diego, Calif., USA) using FlowJo analysis software (Tree Star, Ashland, Oreg., USA), as previously described [19]. 
Macrophage Motility Assays/Cell Spread

To determine the effect of sepsis on macrophage-mediated motility (distance migrated and velocity of migration) from cells derived from septic mice that either have or lack the gene for PD-1, we utilized the in vitro vital microscopic assessment of migration on ICAM-1 assay described by Yang et al. [26] and Elphick et al. [27]. To do this, Delta T dishes (Thermo-Fisher, Pittsburgh, Pa., USA) were coated with mouse ICAM $(10 \mu \mathrm{g} / \mathrm{ml})$ and SDF-1 $(200 \mathrm{ng} / \mathrm{ml}$; R\&D Systems Inc., Minneapolis, Minn., USA). Approximately $5 \times 10^{4}$ peritoneal macrophages, isolated by peritoneal lavage as previously described [19] were washed and added to the Delta $\mathrm{T}$ dish containing $1 \mathrm{ml}$ of L-15 medium plus $2 \mathrm{mg} / \mathrm{ml}$ of glucose. Bright-field or differential interference images were then acquired every $5 \mathrm{~s}$ for $30 \mathrm{~min}$ under a $20 \times$ objective lens using a Nikon TE-2000U inverted microscope. Temperature was maintained at $37^{\circ} \mathrm{C}$ throughout the experiment using an FCS2 live-cell imaging chamber (Bioptechs Inc., Butler, Pa., USA). Cell paths were traced using MetaVue imaging software. Random migration was investigated by adding LPS to media at a final concentration of $1 \mu \mathrm{g} \mathrm{LPS} / \mathrm{ml}$ and analyzed by manually tracing the outline of each cell in selected frames (i.e. at 50-second intervals). The $\mathrm{x}$ and $\mathrm{y}$ coordinates of each cell were determined and the distance moved between intervals measured using ImageJ software (developed by Wayne Rasband, NIH, Bethesda, Md., USA; available at http://rsb.info.nih.gov/ij/index.html) and were then corrected so that the starting position was $\mathrm{x}=0$ and $\mathrm{y}=0$ [26] (an analysis of cell migration for a typical experiment for cells isolated from either $48 \mathrm{~h}$ post-CLP WT or PD-1-/- mice is shown in fig. 1a). Velocity was determined as distance over time independent of direction.

The number of spread cells per field was determined using ImageJ software. In brief, cells were bright-field imaged (no less than 5 randomly chosen fields were captured at each time point) using a Nikon TE-2000U inverted microscope with a $20 \times$ objective lens, initially after $15 \mathrm{~min}$ of adherence to establish a baseline $(0 \mathrm{~min})$ and at $15 \mathrm{~min}$ thereafter.

\section{Trans-Well Migration Assay}

J774 cells were resuspended in HBSS containing 0.02\% BSA and $3 \mu \mathrm{g} / \mathrm{ml}$ Calcein-AM (Molecular Probes by Life Tech., Carlsbad, Calif., USA) at $5 \times 10^{6} \mathrm{~J} 774 \mathrm{cells} / \mathrm{ml}$ and incubated at $37^{\circ} \mathrm{C}$ for 30 min. J774 cells were washed twice and resuspended in HBSS at $1 \times$ $10^{7} / \mathrm{ml}$. One hundred and fifty-microliter J774 cells were placed in the upper chamber of Transwell inserts $(3.0 \mu \mathrm{m}$ pore size, Corning, Corning, N.Y., USA). HBSS with or without $1 \mu \mathrm{M}$ fMLP (as a chemo-attractant) was placed in the bottom chamber, along with either anti-PD- 1 blocking antibody ( 10 or $20 \mu \mathrm{g} / \mathrm{ml}$ ), a Rap1 inhibitor (Ggti at $50 \mu \mathrm{M}$ ) or the phosphatase inhibitor (orthovanadate at $10 \mu \mathrm{M})$. Where appropriate, inserts were coated with a 1:40 dilution of BTI Biomatrix I (Biomedical Tech., Stoughton, Mass., USA). J774 cells were allowed to migrate for $2 \mathrm{~h}$; samples were collected and relative fluorescent intensities were measured using an $\mathrm{FL}_{\mathrm{x}} 800$ Microplate Fluorescence Reader (BIO-TEK Instr., Winooski, Vt., USA). Relative fluorescent intensities were converted to cell numbers from a standard curve utilizing AssayZap Software for Apple Macintosh (BIOSOFT, Cambridge, UK). Duplicate samples for each condition were analyzed, one set comprising $n=1$ [28].

\section{Fluorescence Imaging}

In vitro Cell Line. A suspension of J774 $\left(1 \times 10^{4}\right.$ cells $\left./ \mathrm{ml}\right)$ were incubated with anti-PD-1 blocking antibody or IgG (control) for $90 \mathrm{~min}$. For attachment, these cells were put onto individual cov-

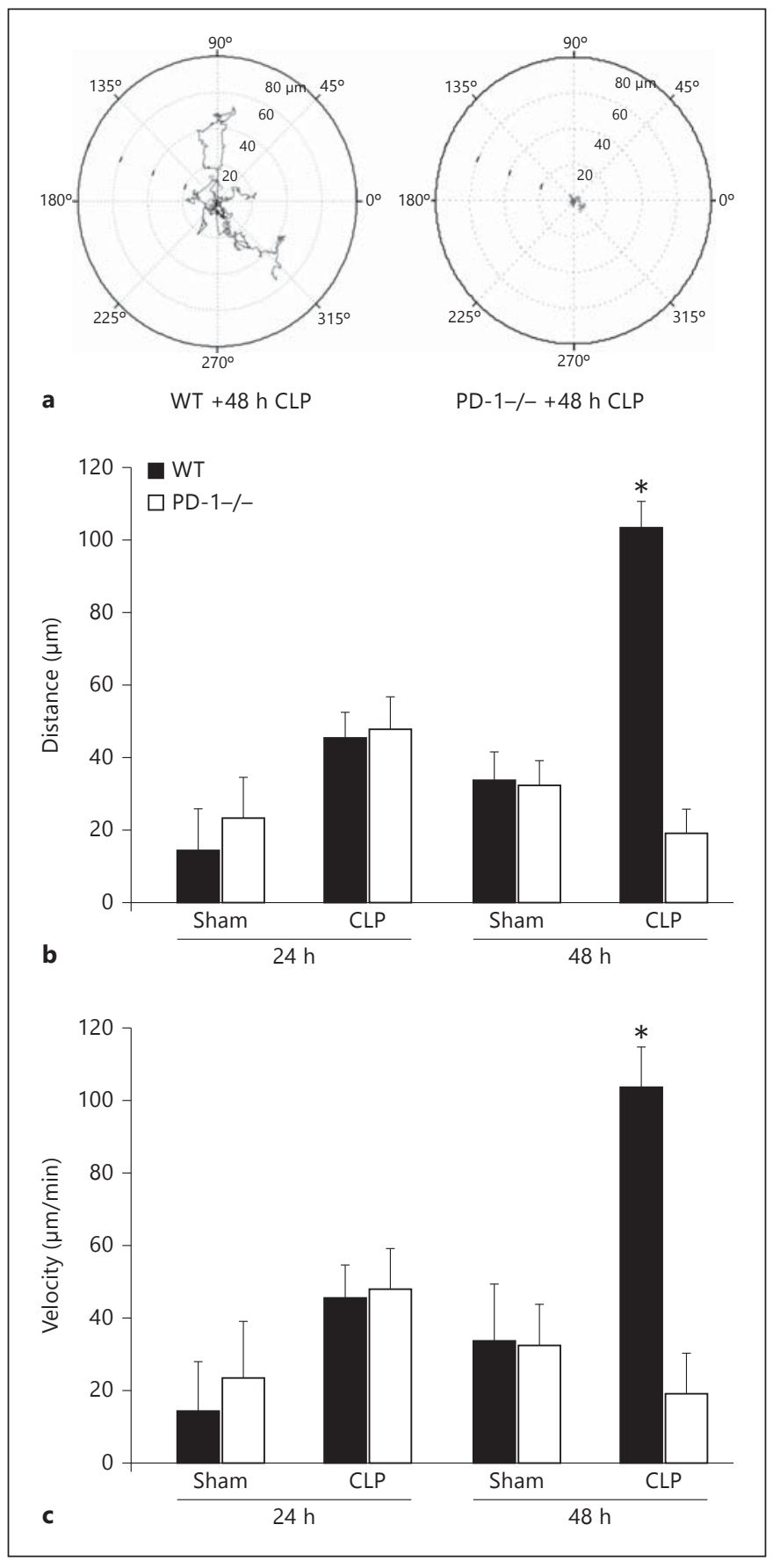

Fig. 1. CLP-induced rise in peritoneal macrophage migratory capacity is reduced by PD-1 gene deficiency. a Representative tracing of mouse peritoneal macrophage migration over time of cells derived from septic $\mathrm{PD}-1-/-$ mice as compared to cells from septic WT mice ( $48 \mathrm{~h}$ post-CLP). b At $24 \mathrm{~h}$, CLP mice macrophages migrate further, but there is no difference in the absence of PD-1. However, at 48 h, CLP PD-1-/- mice had greatly reduced migratory distance when compared to CLP WT mouse cells, but again with no differences in the Sham groups. c Similar results were seen in motility. ${ }^{*} \mathrm{p}<0.05$ versus PD-1-/- CLP ( $\mathrm{n}=5-6$ per group), determined by ANOVA followed by Tukey's test. 
erslips for $60 \mathrm{~min}$. Subsequently, 95\% ethanol was added onto each coverslip, followed by $100 \%$ ethanol for fixation. After washing, the cells were incubated with anti-F-actin or anti- $\alpha$ actinin rabbit antibodies (Sigma, St. Louis, Mo., USA) for 90 min, washed, and then incubated with the secondary anti-rabbitFITC conjugated antibody for another $90 \mathrm{~min}$. Finally, coverslips were washed and fixed with $4 \%$ paraformaldehyde (Sigma) for $45 \mathrm{~min}$ at room temperature, then mounted with mounting medium containing the blue nucleic acid dye DAPI (Vector Laboratories, Burlingame, Calif., USA). Utilizing a Nikon Eclipse E400 (Nikon Inc., Mellville, N.Y., USA) microscope, Mercury 100 W light source (Chui Technical Corp., King's Park, N.Y., USA) and Polaroid DMC-3 digital camera (Polaroid, Cambridge, Mass., USA) macrophages were identified by their DAPI-stained nuclear morphology and examined for their respective antibody staining.

Ex vivo Peritoneal Leukocytes. WT background (C57BL/6J) or PD-1-/- mice were subjected to Sham (control) or CLP, which induces polymicrobial sepsis. The macrophages in the peritoneal lavage from Sham and CLP mice were collected $24 \mathrm{~h}$ after the procedures and concentrated on to glass microscope slide by cytospinning. The cyto-spun cells were then examined for changes in their cytoskeletal morphology by florescence microscopy (viewed under a $20 \times$ objective lens) following staining with either anti- $\alpha$ actinin or anti-F-actin, as mentioned above. In some cases ex vivo harvested cells were immune stained for the concomitant expression of PD-1 as opposed to CD11b relative to DAPI-stained nuclei. Confocal images were acquired with a Nikon PCM 2000 (Nikon Inc.) using the Argon (488) and the green Helium-Neon (543) lasers. Images were collected with a $20 \times$ Plan Fluor lens and a $1 \times$ scan zoom. $0.25-\mu \mathrm{m}$ optical sections were made through selected macrophages expressing signals for both PD-1 and CD 11 b to assess not only the extent to which PD-1 expression co-localized with the signal for CD11b, but also the degree to which observations being made were of cell surface nature as opposed to being internalized or phagocytized.

\section{Immune-Precipitation and Western Blot Analysis}

Peritoneal cells from Sham or CLP mice were collected $24 \mathrm{~h}$ after surgery by lavage with PBS, lysed in lysis buffer, and protein content was determined using the Bio-Rad protein assay reagents (Bio-Rad, Hercules, Calif., USA). Two hundred and fifty micrograms of cell lysates were then incubated with either CD11b antibody (4 mg per reaction, clone M1/70; Biolegend, San Diego, Calif., USA) or isotype IgG and protein A/G PLUS-agarose beads (10 ml, SC-2003; Santa Cruz Biotechnology Inc., Santa Cruz, Calif., USA) overnight at $4^{\circ} \mathrm{C}$ [29]. After washing with PBS, the beads were resuspended in loading buffer and boiled for $3 \mathrm{~min}$. The immune-precipitated solution was used to assess the presence of PD-1 by Western immunoblot, as previously described [30]. In brief, samples were separated on $16 \%$ SDS polyacrylamide gels and transferred to polyvinylidene fluoride membranes (Life Technologies, Grand Island, N.Y., USA). The membranes were blocked with $5 \%$ non-fat milk in Tris-buffered saline with $0.05 \%$ Tween-20 and incubated with anti-mouse PD-1 (clone RMP1-30; Biolegend) antibody overnight at $4{ }^{\circ} \mathrm{C}$. Membranes were washed and incubated with horseradish peroxidase-conjugated secondary antibody. After washing, proteins were visualized by ECL and densitometrically assessed by an Alpha Innotech image analyzer (Alpha Innotech, San Leandro, Calif., USA).

\section{Phagocytosis Assay}

Peritoneal leukocytes isolated from Sham or CLP mice as described above were plated in 6-well tissue culture plates at $4 \times 10^{6}$ cells $/ \mathrm{ml} /$ well and incubated in complete RPMI 1640 medium at $37^{\circ} \mathrm{C}$. Ninety minutes later, non-adherent cells were washed off with PBS. The adherent macrophages were then co-cultured with $\sim 60 \mu \mathrm{g}$ of pHrodo $^{\mathrm{TM}}$-conjugated Escherichia coli BioParticles ${ }^{\circledR}$ (Molecular Probes by Life Tech., Carlsbad, Calif., USA) in PBS at $37^{\circ} \mathrm{C}$ for $1 \mathrm{~h}$ and washed completely with PBS. Cells were harvested by scraping, resuspended in PBS containing sodium azide, and the extent of fluorescent BioParticle ${ }^{\circledR}$ was detected by flow cytometry as described previously [19]. The percentage of cells containing fluorescent BioParticles ${ }^{\circledR}$ was then determined and used as an index of the phagocytic capacity of these cells.

\section{Statistical Analysis}

Data are shown as the mean \pm SEM and analyzed with the Mann-Whitney rank-sum test for frequency and intensity data. Parametric data were analyzed by ANOVA followed by Tukey's test for multiple comparisons as indicated. Groups were considered statistically significantly different at a $\mathrm{p}$ value of $<0.05$.

\section{Results}

\section{CLP Induces an Increase in Macrophage Migration/ Motility That Is Mitigated by Deficiency in PD-1 Gene Expression}

Although we observed a trend towards an increase in macrophage migration and the velocity of movement at $24 \mathrm{~h}$ post-CLP, this was not statistically significant. However, following $48 \mathrm{~h}$ of exposure to CLP a marked increase in migration and motility $(\mathrm{p}<0.05)$ in peritoneal macrophages isolated from WT septic mice as compared to animals subjected to Sham protocol was evident (fig. 1a-c). Alternatively, septic PD-1-/- mouse macrophages showed no such rise in migration when compared to both Sham groups (fig. $1 \mathrm{a}-\mathrm{c} ; \mathrm{p}<0.05$ ). We also observed that macrophages harvested from WT septic mice exhibited a substantial increase in the number of spread cells per field when compared to septic PD-1-/- mice (fig. 2a, b). Alternatively, cells obtained from WT Sham animals exhibited a markedly lower number of spread cells ( $\sim 1 / 3$ less) than the cells taken from CLP mice. Also, unlike the WT CLP mouse cells, the cells derived from the animals subjected to only the Sham protocol, when followed over $15 \mathrm{~min}$ in culture, continued to attach (become spread). Importantly, this ability to continue to attach/spread was also evident in the PD-1-/- mouse cells irrespective of whether derived from either Sham or CLP animals. One other marked difference between the PD-1-/- and the WT mouse cells was the initial extent of the number of attached/spread macrophages seen when allowing them to adhere to plastic, whereby, 


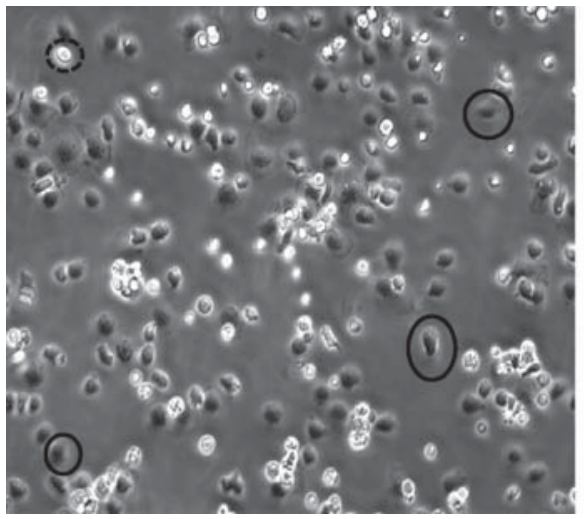

WT (15 $\mathrm{min})$ at $48 \mathrm{~h}$ post-CLP

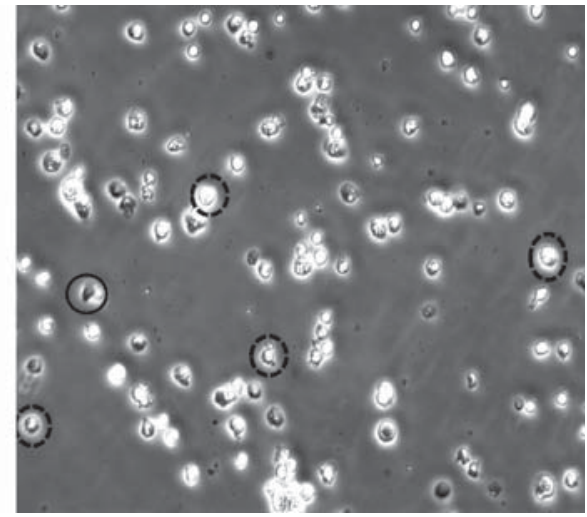

PD-1-/- (15 $\mathrm{min})$ at $48 \mathrm{~h}$ post-CLP

a $\bigcirc=$ spread cell

Fig. 2. CLP-induced increase in the number of spread macrophage per field is reduced by PD-1 gene deficiency. a Representative images of macrophage monolayers derived from WT and PD-1-/- CLP illustrating the reduced number of spread cells typically seen on ICAM-1-coated plates $(\times 20)$. b Summary data number of spread cells per field at 0 and $15 \mathrm{~min}$ (mean \pm SEM for 3 repeat experiments), which illustrates that the macrophages derived from CLP WT mice exhibited a marked increase in the number of spread cells per field when compared to cells from PD-1-/- CLP mice. * $\mathrm{p}<0.05$ WT versus PD-1-/-; ${ }^{\#} \mathrm{p}<0.0515$ min group versus 0 time; ${ }^{\dagger} \mathrm{p}<0.05$ Sham versus CLP; determined by the Mann-Whitney rank-sum test.

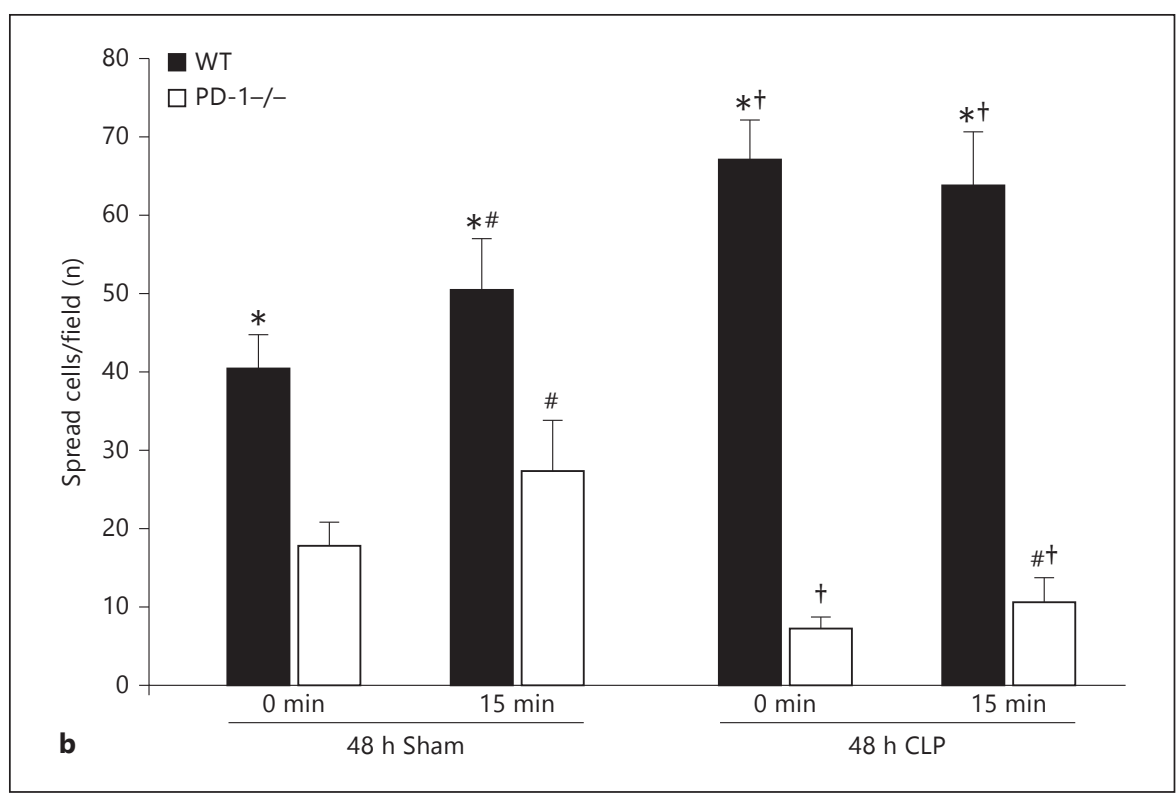

PD-1-/- macrophages were substantially lower when compared to WT mouse macrophages (a $~ 50 \%$ reduction in the number of spread cells was seen within the comparative Sham groups and $\sim 80-90 \%$ decline in the number of spread cells was seen within the comparative CLP groups; fig. 2b).

\section{CLP Induces a Decline in Macrophage Bacterial}

Phagocytic Function That Is Mitigated by Deficiency in PD-1 Gene Expression

Since phagocytosis is a central process both to the development of a competent functional innate as well as adaptive immune response, and also requires utilization/ re-arrangement of the cell's cytoskeletal structures, we attempted to assess the comparative impact of CLP-induced sepsis on peritoneal macrophage phagocytic func- tion in the presence or absence of PD-1 gene expression. In keeping with our prior observation [19], CLP mouse peritoneal macrophages exhibited a markedly reduced ability to phagocytose opsonized bacteria (fig. 3a, b). However, that capacity to phagocytose bacteria by peritoneal macrophages derived from PD-1-/- CLP mice was restored to Sham-mouse cell levels (fig. 3a, b).

\section{Pre-Treatment of the Mouse Macrophage Cell Line, \\ J774, with Antibodies against PD-1 Alters Cell \\ Cytoskeletal Structure/Staining (for $\alpha$-Actinin and F-Actin)}

Since the results of the prior experiments indicated that the PD-1 gene product is involved directly and/or indirectly in inducing changes in peritoneal macrophage 


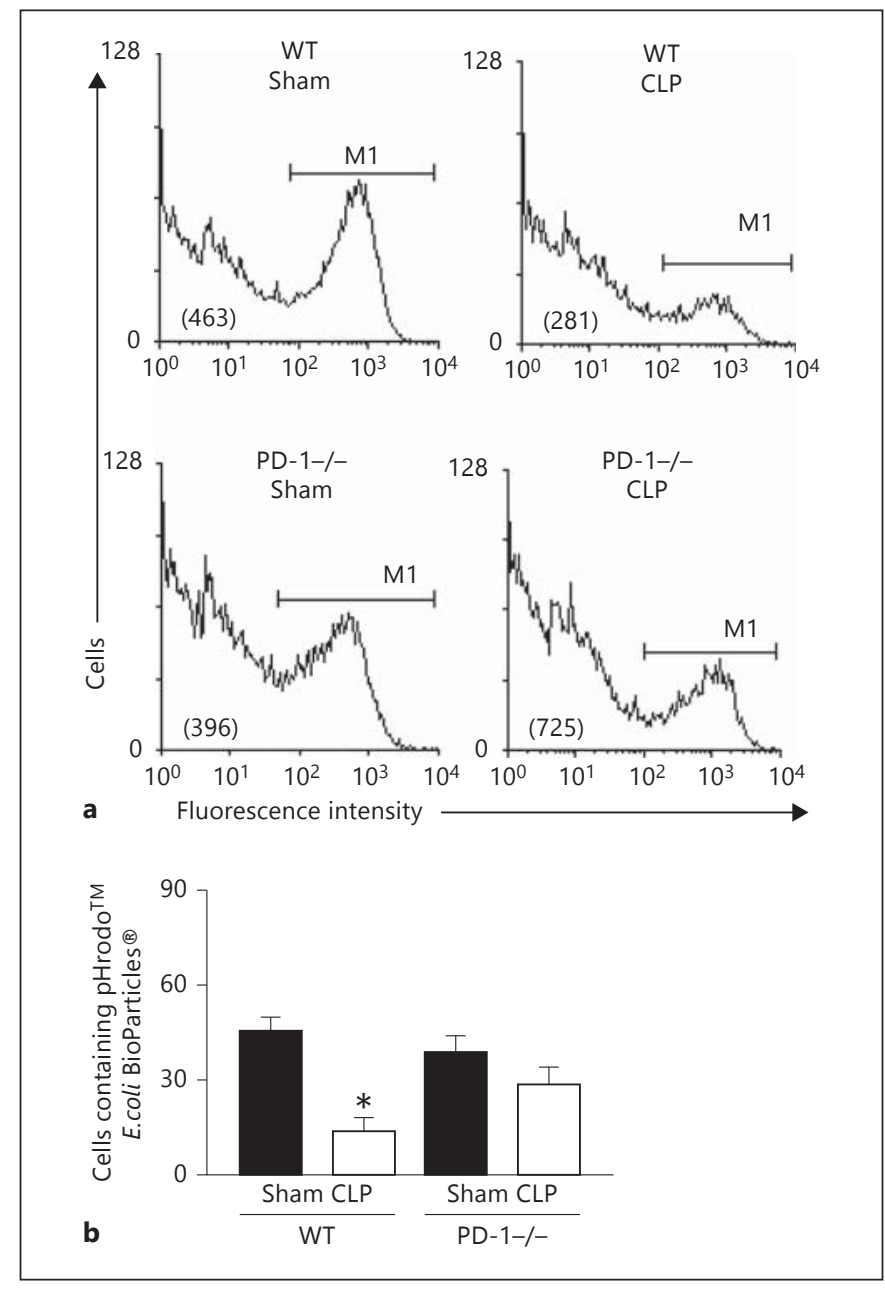

Fig. 3. CLP-induced suppression of bacterial phagocytosis is reversed by PD-1 gene deficiency. a Typical FACS histograms of peritoneal macrophages that had been isolated by adherence from WT Sham, WT CLP, PD-1-/- Sham or PD-1-/- CLP mice and then co-cultured with pHrodo ${ }^{\mathrm{TM}}$-conjugated E. coli BioParticles ${ }^{\circledR}$ for $1 \mathrm{~h}$. Cells were detached and assessed for their extent of E. coli BioParticles ${ }^{\circledR}$ fluorescence intensity (mean fluorescence intensity is provide in parentheses) by flow cytometry. A region, M1, in which a cell was considered positive for containing fluorescent E. coli BioParticles ${ }^{\circledR}$, was established by comparison with a negative control that was run at $4^{\circ} \mathrm{C}$ as opposed to the $37^{\circ} \mathrm{C}$ used in all other cases. $\mathbf{b}$ Summary data for repeated assessments of macrophage preparations from 6-10 independent animals for a given treatment group. Data is presented as mean \pm SEM. Asterisk $(*)$ indicates the presence of a significant difference $(\mathrm{p}<0.05)$ between treatment groups as determined by the Mann-Whitney rank-sum test.

migratory/motile capacity and cell spreading, as well as changes in phagocytic function, we wanted to determine if this was a result of the direct ligation of PD- 1 on the cell surface. To assess this we treated mouse J774 cells (which express PD-1 by flow cytometry; fig. 4a) with anti-PD-1 antibody or a mouse IgG control antibody for $90 \mathrm{~min}$, then permeabilized and stained the adherent cells with either anti-mouse $\alpha$-actinin or anti-mouse F-actin along with the nuclear stain DAPI (fig. $4 \mathrm{~b}-\mathrm{e}$ ). What we observed was that cells treated with anti-PD-1 antibody exhibited aggregation as well as a punctate pattern in their staining for $\alpha$-actinin (fig. 4c) and to a lesser degree for F-actin (fig. 4e), as opposed to a more even or homogeneous expression observed with mouse IgG control antibody treated J774 cells (fig. 4b, d).

As these findings suggest that binding PD-1 leads to cytoskeletal element rearrangement and, as we have shown here that the processes such as macrophage migration and motility, spreading and phagocytic function, which require rearrangement of these same cytoskeletal structures, are also altered by sepsis, we felt it was important to determine the extent to which the expression of $\alpha$-actinin and/or F-actin on mouse peritoneal macrophages were also altered by the presence or absence of PD-1 gene product expression during the response to experimental sepsis in vivo. What we saw here was that when comparing peritoneal macrophages derived from CLP WT mice to cells derived from Sham animals, the septic mouse cells not only were more spread and irregular in shape, but also exhibited a more heterogenous/punctate pattern of staining for both $\alpha$-actinin or F-actin as with the anti-PD-1-treated J774 cells (fig. 5a, b, e, f). Alternatively, macrophages isolated from PD-1-/- CLP mice lack the spreading seen in the septic WT mouse cells and their a-actinin or F-actin staining was comparable to what was seen in both the WT or PD-1-/- Sham mouse cells expression (fig. 5a, c, d, e, g, h).

\section{CLP Induces a Rise in Both PD-1 and PD-L1}

Expression on F4/80+ Cells and the Rise in PD-L1 Is

Not Affected by the Loss of PD-1 Gene Expression

While we have previously shown that following the CLP there is a marked rise in blood monocyte and peritoneal macrophage PD-1 levels [19], it was not clear whether or not expression of the most ubiquitous ligand for PD-1, PD-L1, was similarly affected by experimental sepsis, and also how it might be affected by the absence of the gene for PD-1. Here we observed, as we reported previously [19], that in as little as $12 \mathrm{~h}$ after CLP a rise of $\mathrm{PD}-1+$ expressing in peritoneal $\mathrm{F} 4 / 80+$ macrophages can be seen and this lasts through $48 \mathrm{~h}$ (fig. 6a, b). Interestingly, the percentage of PD-L1+ cells was also markedly elevated (greater than $80 \%$ positive) in this same F4/80+ cell population (fig. $6 \mathrm{~b}$ ); however, the lack of 


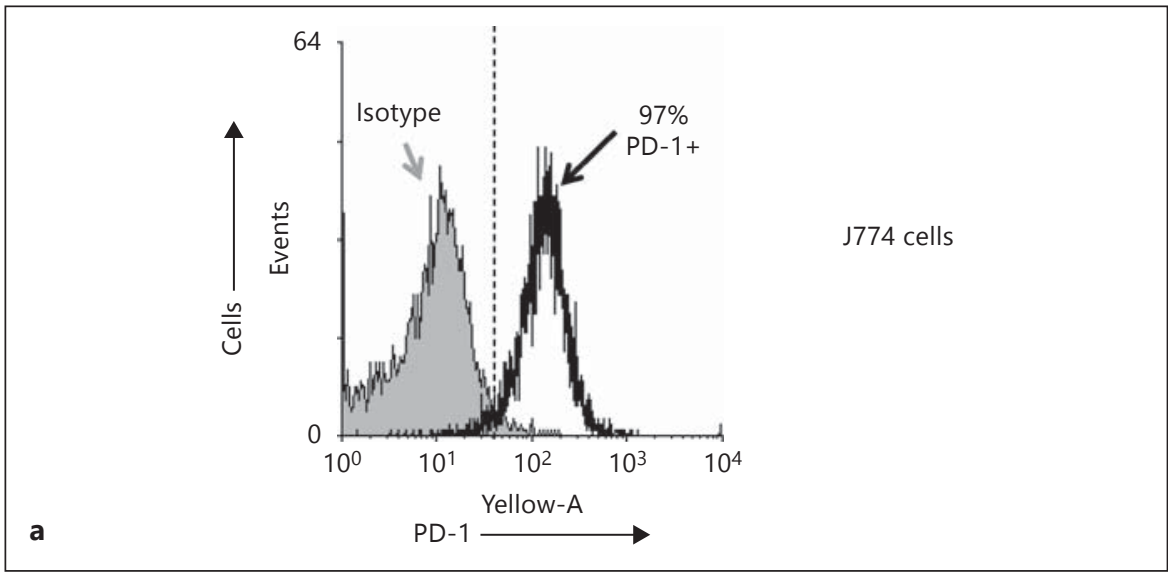

Fig. 4. J774 cells exhibit altered cytoskeletal immunefluorescent staining pattern for either anti- $\alpha$-actinin or anti-F-actin when incubated with anti-PD-1 blocking antibody but not control IgG. a Staining J774 cells with anti-PD-1 show that $\sim 97 \%$ of cells are PD-1+, as determined by flow cytometry and depicted in the representative histogram. b, c Differences typically observed in the $a$-actinin-stained cells [in green for FITC- vs. DAPI-stained nuclei (blue); magnification $\times 40$ ] treated with a non-specific IgG (control antibody; b) versus those treated with anti-PD-1 (c). Arrows point to area aggregations that contribute to a punctate pattern of their staining for a-actinin. d, e Illustration of the staining pattern typically observed in the F-actinstained cells [in green for FITC- vs. DAPIstained nuclei (blue); magnification $\times 40$ ] treated with a non-specific-IgG (control antibody; d) versus those treated with antiPD-1 (e).
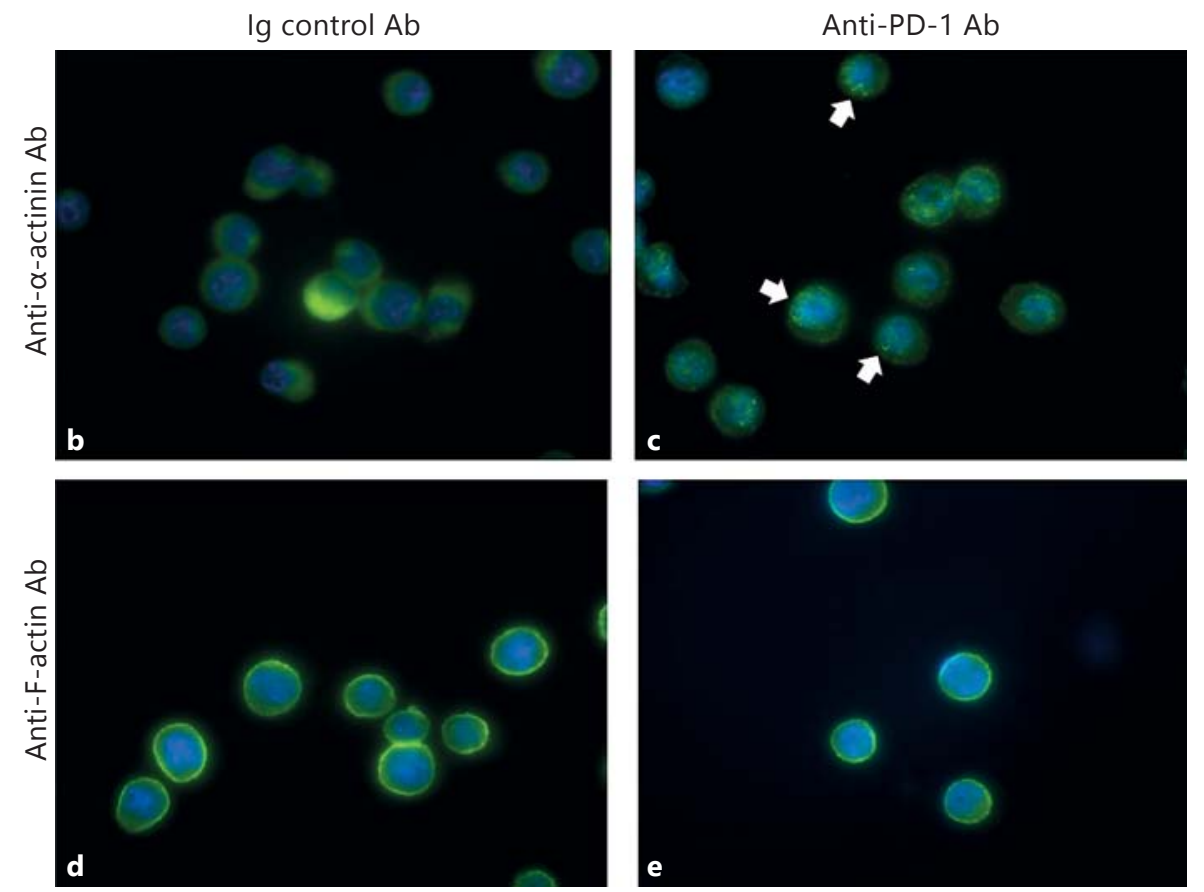

PD-1 gene expression did not attenuate this rise in PDL1 in any fashion. While not shown, a similar relationship was seen with the PD-1 or PD-L1 expression on CD11b+ cells.

The CLP-Induced Increase in Peritoneal Macrophage

Migration Involves Activation of SHP-1, SHP-2 and

\section{RAP1}

Most studies that have examined intracellular signaling induced by the ligation of PD-1 indicate that it leads to the recruitment and activation of the phosphatases SHP-1 and SHP-2, which in turn antagonize the activation of Akt/PI3K [21]. However, recent work by Schnei- der et al. [20] and Owada et al. [31] suggest the signaling through co-inhibitory receptors like PD-1, such as CTLA4 or BTLA, may also activate components of cell cytoskeleton and/or associated leukocyte adhesion molecules like the integrin family of receptors, implying a mechanism by which PD-1 can have an effect on aspects of migration and phagocytosis. Therefore, we attempted to assess the impact of either blocking antibodies, non-specific phosphatase inhibition (using orthovanadate treatment) or selective inhibition of RAP1 (Ggti inhibitor), a signaling protein involved in activation of the cytoskeleton [3234], on the bacterial peptide (fMLP)-induced increase in J774 cell migration (fig. 7). We observed that not only 
Sham
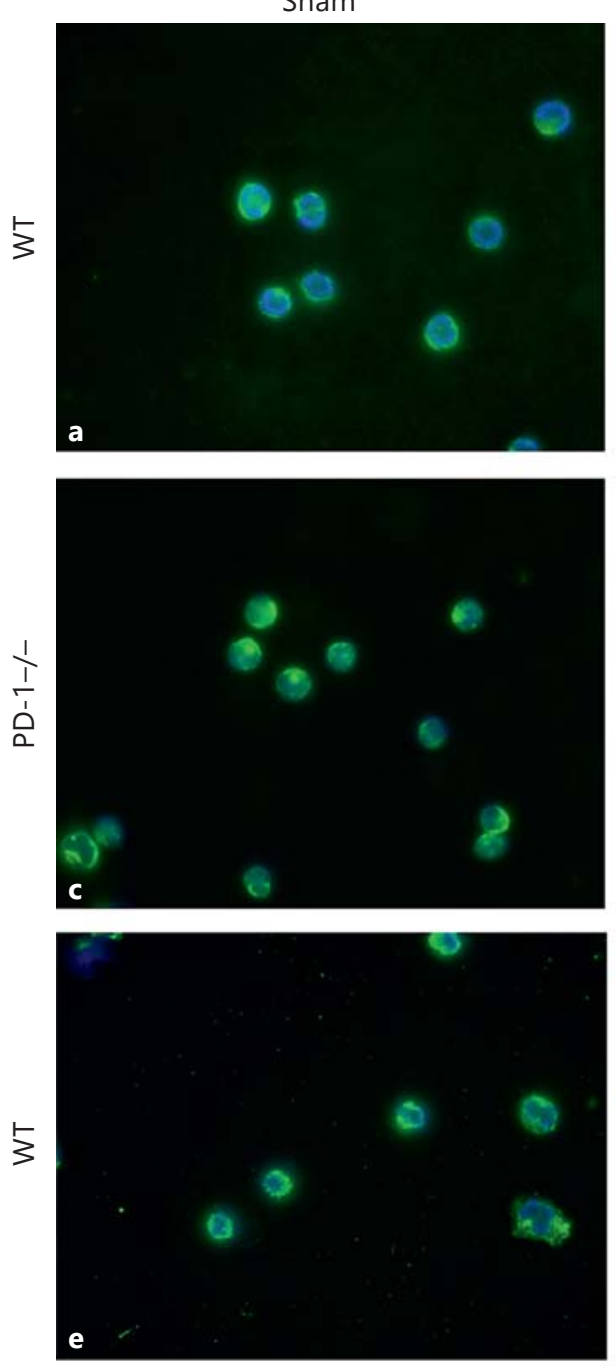

Fig. 5. Experimental sepsis induces alterations in peritoneal macrophage cytoskeletal staining that are attenuated in cells derived from mice lacking PD-1. Peritoneal macrophages derived from WT CLP mice (after $24 \mathrm{~h}$ ), but not cells from PD-1-/CLP mice, exhibit a more irregular and spread cell morphology and a punctate pattern of fluorescent $\alpha$-actinin (arrows; $\mathbf{a}$-d) or F-actin (e-h) staining (in green for FITC) that is not seen in either of the treated Sham group's cells (DAPI nuclear counter stain in blue).

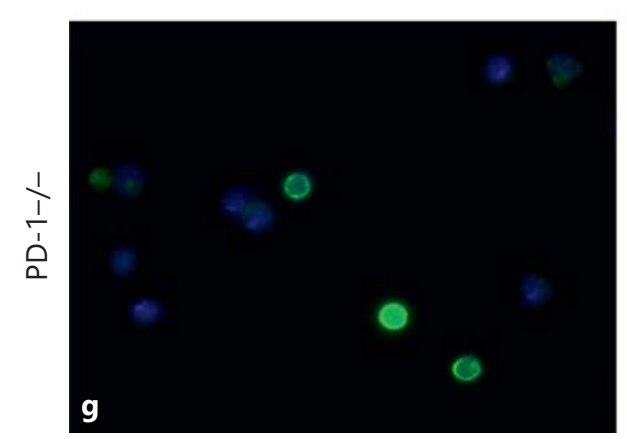

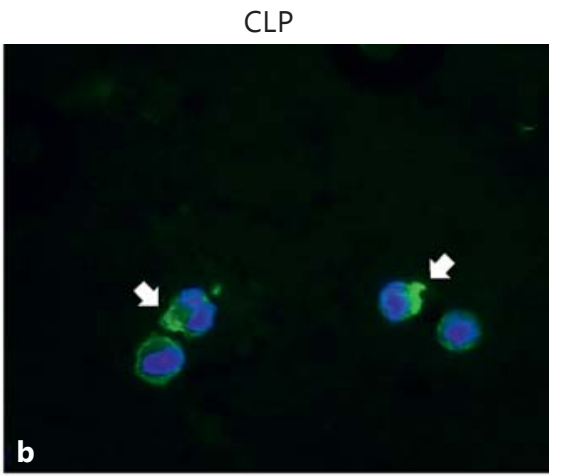
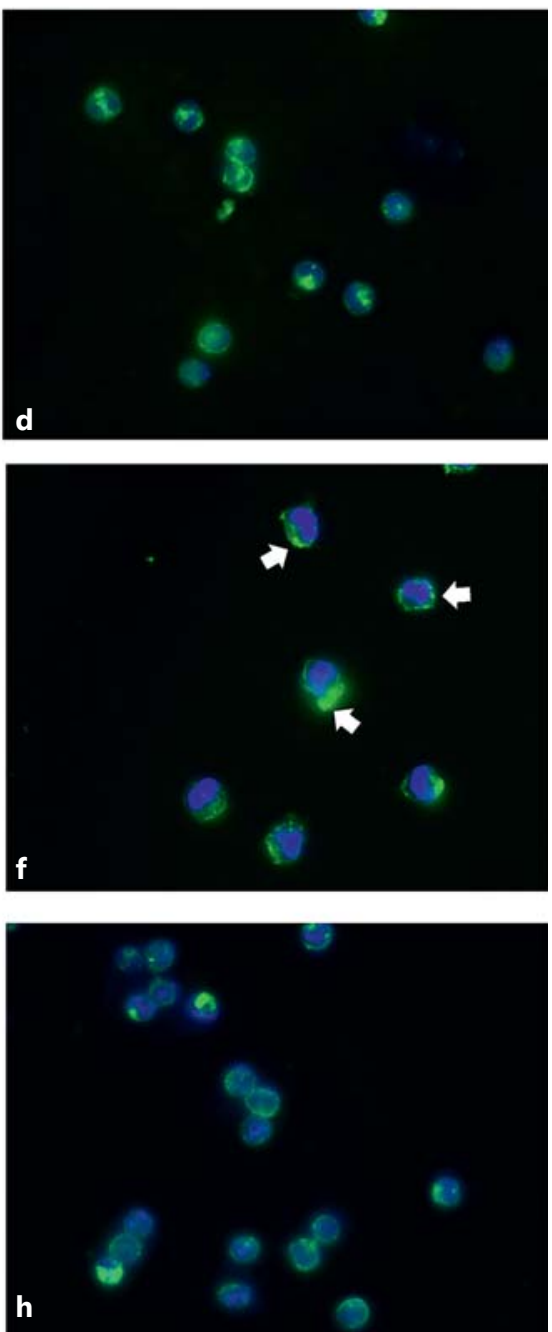

could we antagonize/inhibit fMLP-induced migration by using PD-1 blocking/antagonistic antibodies, but that fMLP-induced migration was even further suppressed by treatment of these cells with the non-specific phosphatase inhibitor, orthovanadate, or the selective Rap1 inhibitor, Ggti (fig. 7).

\section{PD-1 Co-Localizes with CD11b on Septic Mouse \\ Peritoneal Macrophages}

The work of Schneider et al. [20] evaluating co-inhibitory receptors, such as CTLA-4, suggested that intercellular adhesion molecules such as the $\beta$-integrins may also be affected by the increased expression of co-inhib- 
Fig. 6. Sepsis induces increased expression of PD-1 and its ligand on F4/80+ cells. a Experimental sepsis produced by CLP induces upregulation of the percentage of WT mouse peritoneal macrophages (gated as F4/80+) expressing PD-1. b While mice lacking the PD-1 gene (PD-1-/-) product exhibited no detectable PD-1 on their peritoneal macrophages (left), they still upregulated the percentage of macrophages that were PD-L1+ to the same extent and fashion as WT CLP animal cells (right). Summary data is presented as mean \pm SEM derived from $n=6-8$ independent mouse macrophage preparations assessed per treatment group. Asterisk $(*)$ indicates the presence of a significant difference when $\mathrm{p}<0.05$ between CLP and Sham treatment for the equivalent genetic mouse background animals as determined by the Mann-Whitney rank-sum test. ND = Not detected.

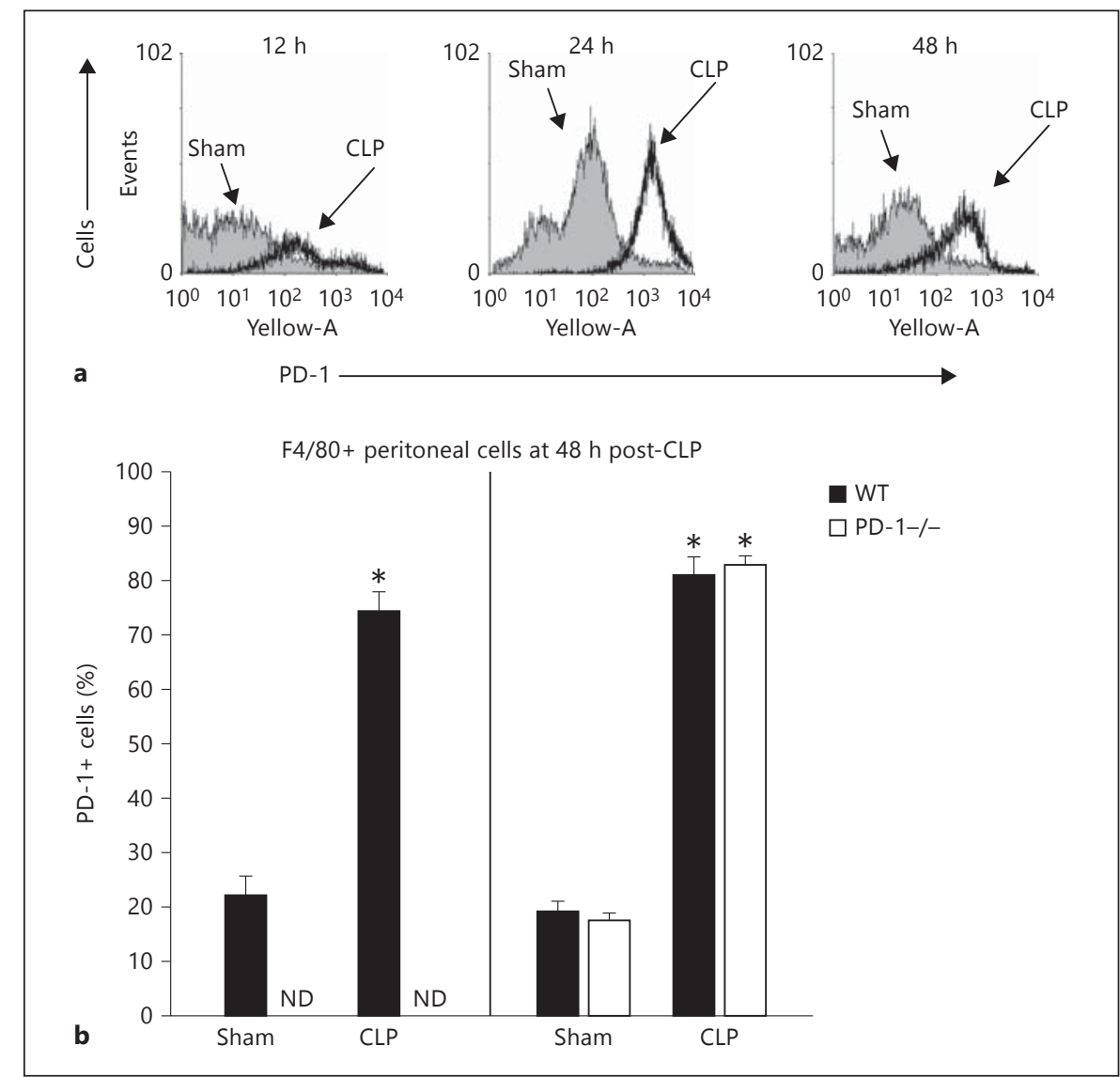

itory molecules like PD-1 [22]. Using immune-staining co-localization by confocal imaging, we attempted to determine the extent to which PD-1 antigen/receptor expression was associated or interacts with a member of the integrin family, CD11b. Figure $8 \mathrm{a}$ and b illustrate that following CLP-induced PD-1 expression was markedly increased on peritoneal macrophages also expressing CD11b. Furthermore, we observed marked colocalization of PD-1 and CD11b on the cell surface of a number of peritoneal macrophages (fig. 8a), which was supported by three-dimensional reconstruction of these cells by Z-stack analysis (online suppl. fig. 1; for all online suppl. material, see www.karger.com/ doi/10.1159/000355888). Interestingly, within a number of these cells we also saw what appeared to be endosomal structures containing only PD-1 (fig. 8a; online suppl. fig. 1), but not CD11b. Finally, we observed that when anti-CD11b was utilized as a pull-down antibody, immune-precipitated PD-1 was markedly increased in cell lysates derived from CLP mice compared to Sham mice (fig. 8b).

\section{Discussion}

Previous studies from our laboratory $[19,35]$ and others [36-38] have recently demonstrated that signaling via PD-1:PD-L1 may have a significant impact on developing morbidity and mortality encountered during sepsis in not only experimental animals, but also humans. Studies with PD-1 gene-deficient mice, as well as neutralizing antiPD-1 antibody treatment in septic animals, point to an impact on the adaptive immune responsiveness. These changes include the restoration of delayed-type hypersensitivity and a reduction of sepsis-induced lymphocyte cell death, as well as changes in innate immune responses, such as the suppression of the systemic inflammatory response and restoration of declining phagocytic and/or altered migratory capacity $[19,35,38]$. PD- 1 is expressed on a variety of immune cells besides just $\mathrm{T}$ cells (on which it has been most extensively considered as a mediator of the adaptive immune response) [36-38], such as monocytes and tissue macrophages $[19,35,38]$. Also, while downstream signaling through SHP-1/2 are the best un- 


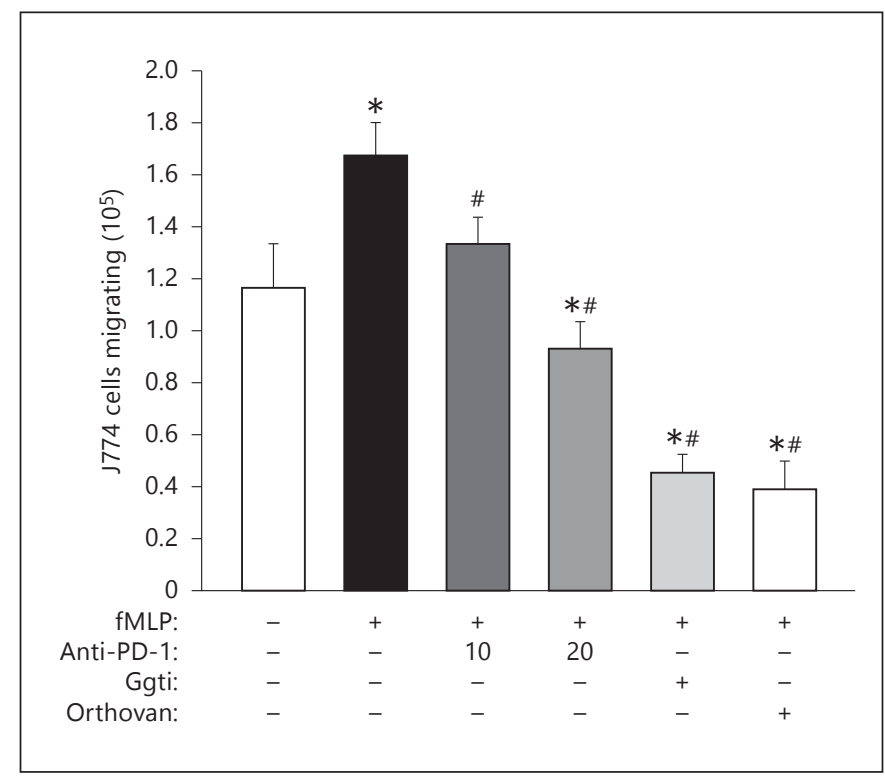

Fig. 7. Treatment of J774 cells with either antibody to inhibit PD-1 ligation, or pharmacological inhibitors to its downstream signaling, inhibit cell migratory capacity. Determination of the effect of anti-PD-1 blocking antibody (10 or $20 \mu \mathrm{g} / \mathrm{ml})$, a Rap1 inhibitor (Ggti at $50 \mu \mathrm{M}$ ) or the phosphatase inhibitor (orthovanadate at 10 $\mu \mathrm{M})$ on fMLP $(1 \mu \mathrm{M})$ induced $\mathrm{J774}$ cell TransWell migration (see Methods for details). Summary data is presented as mean \pm SEM from 3 repeat experiments. ${ }^{*} \mathrm{p}<0.05$ versus no treatments and no fMLP stimulation control group (far left open bar group); ${ }^{\#} \mathrm{p}<0.05$ versus fMLP stimulation alone control group (2nd solid black bar on left side); as determined by ANOVA followed by Tukey's test.

derstood pathways involved in regulating functional changes seen in cells that express PD-1 [21], especially of the lymphoid lineage, little is known as to whether this same pathway is involved in mediating functional changes in phagocytes that express PD-1. There is emerging evidence suggesting that downstream signaling via related ITIM-like receptors, e.g. CTLA-4, may involve signaling molecules outside the SHP-1/2 family $[20,22]$. In light of our recent observation that septic mouse and human monocytes/macrophages rapidly exhibit increased expression of the co-inhibitory cell surface protein $\mathrm{PD}-1$ [19] and for the reasons just mentioned, we have examined whether PD-1 expression effects the migration and motile capacity of macrophages after septic insult while also beginning to assess where this might be occurring.

Here, we have shown that following CLP there is a decline in phagocytic capacity (we have previously shown that this occurs with both opsinized and non-opsinized targets [19]) and that migratory capacity, both in rate and direction, along with cell spreading following surface ad- herence, were markedly increased in septic WT animal cells and were, inversely, reduced to control/Sham mouse cell levels by PD-1 gene deficiency. We found that these changes in migratory/cell spreading capacity and their suppression in PD-1-deficient mouse cells appear to be substrate independent as this occurs in the presence or absence of ICAM-1 or fibronectin versus plastic alone (data not shown). This situation demonstrates the independence of the changes in phagocytic capacity irrespective of the opsinization status of the targets.

As migration and/or phagocytosis are dependent on cytoskeletal rearrangements for regulation, we examined the influence of PD-1:PD-L ligation in altering the cytoskeleton by using a blocking antibody directed against PD-1 on a mouse macrophage J774 cell line. Interestingly, we found that in the presence of the anti-PD-1 antibody there was an increase in both cell spreading and that the staining pattern for $\alpha$-actinin became more punctate in nature (less evenly distributed). The difference in Factin staining, while evident (like $\alpha$-actinin) in the antiPD-1-treated J774 cells, was considerably less overt in the anti-PD-1-treated septic mouse peritoneal macrophages than the isotype-treated CLP animal cells. Importantly, we observed that while the WT CLP mouse cells exhibited both spreading and a punctuated staining pattern for both $\alpha$-actinin and F-actin, this phenotype was reduced back to Sham appearances in the CLP PD-1 gene-deficient mice. Together, these data support the concept that the changes seen in migratory and/or phagocytic capacity are associated with changes in cytoskeletal re-organization, and, importantly, this is affected directly or indirectly by the lack of PD-1 gene expression.

Studies by Schneider et al. [22] suggest that signaling through related co-inhibitory molecules like CTLA- 4 can interact with or activate components of the cytoskeleton via activation of the small GTPase family member RAP1. However, the evidence for similar activity in lymphocytes, let alone macrophages, expressing PD-1 is not known. To determine whether inhibiting PD-1 via antiPD-1 neutralizing antibody or by pharmacological inhibition of downstream PD-1 signaling via phosphatases, such as SHP-1/2, that are recruited by PD-1 during receptor ligation/activation [21], or blockade of RAP1 activation, with the inhibitor Ggti, lead to oblation of the migratory capacity/phenotype, we again utilized the mouse macrophage J774 cell line and induced migration to fMLP. We found that not only the migration to fMLP was attenuated by neutralizing antibodies against PD-1 in a dose-dependent fashion, but also this was markedly further suppressed by treatment of these cells with either the 
Fig. 8. PD-1 co-localizes with CD11b on septic mouse peritoneal macrophages. a Representative three-color immunofluorescence staining of adherent peritoneal macrophages derived from Sham or CLP WT mice at $24 \mathrm{~h}$ post-CLP for the nucleus (DAPI), CD11b (anti-CD11b) and PD-1 (anti-PD-1) co-localization. b Results of a typical Western immunoblot analysis for PD-1 expression on immunoprecipitated protein (IP) samples obtained from the cell lysates of peritoneal macrophages harvested from Sham versus CLP mice using anti-mouse CD11b antibody or IgG control. c Summary/repeated integrated densitometric values (IDV) of PD-1 expression for CD11b IP samples are provided in the histogram. Data is presented as mean \pm SEM derived from $\mathrm{n}=4-8$ independent mouse macrophage preparations assessed per treatment group. Asterisk $(*)$ indicates the presence of a significant difference $(\mathrm{p}<$ 0.05 ) between CLP and Sham treatment animals as determined by the Mann-Whitney rank-sum test.

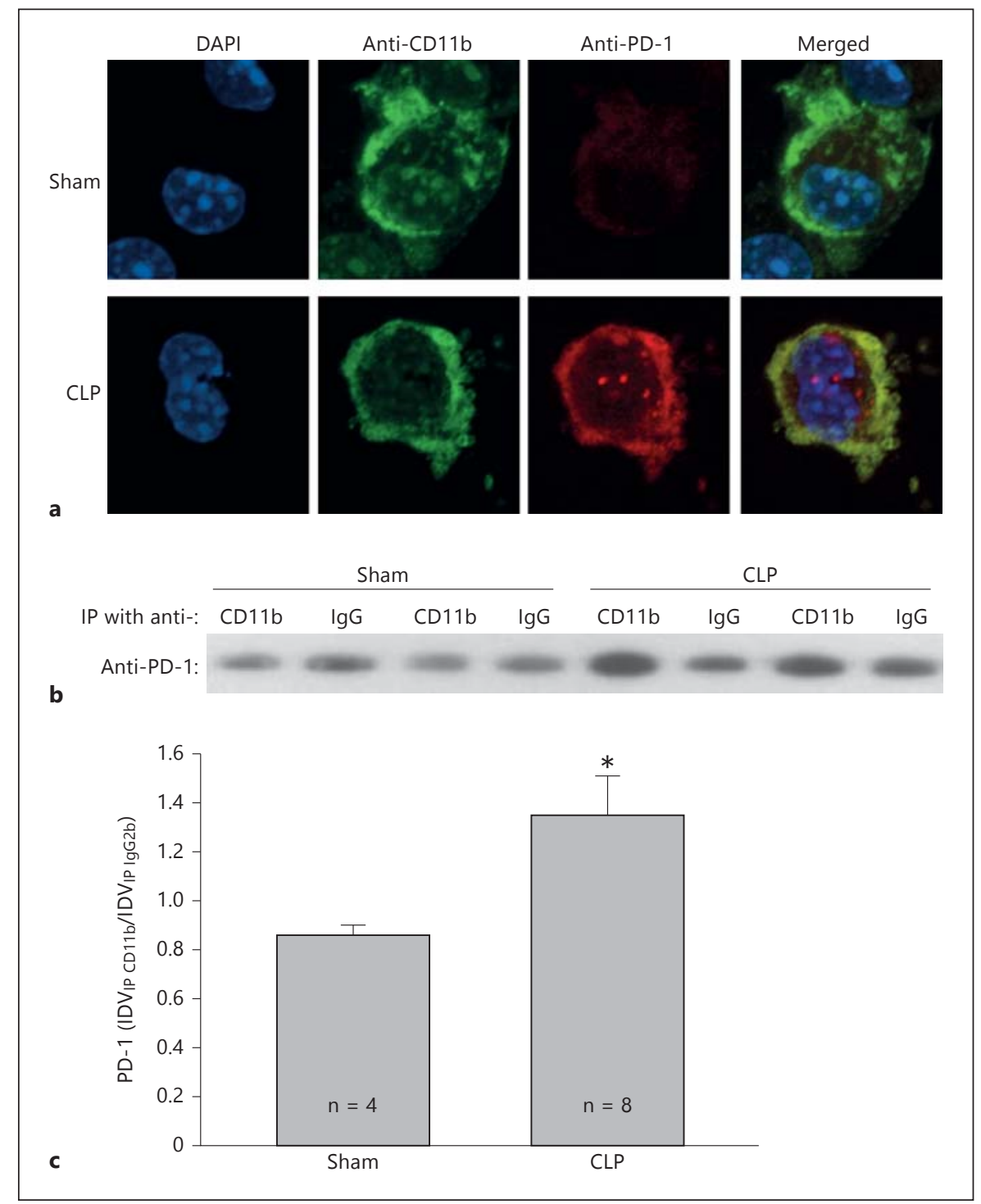

non-specific phosphatase inhibitor orthovanadate or the RAP1-selective inhibitor Ggti. This strongly suggests that the PD-1 downstream signaling via both phosphatase and RAP1 recruitment/activation are needed to alter the migratory phenotype induced in response to PMLP ligation. While this indicates the need for downstream signaling, it does not preclude that these effects may be the result of the indirect action of an anti-inflammatory/pro-migratory agent or mediator's action on this process. Interestingly, we have found that pro-inflammatory cytokine release capacity in response to LPS challenge (which is markedly suppressed in WT background CLP mouse peritoneal macrophages) is significantly increased in PD-1 knock-out CLP mouse cells; however, it still re- mains almost four times lower than Sham mouse/naïve animal's cells capacity to respond to such stimulation [19]. A similar response is also evident in human blood monocytes from septic shock patients $[19,38]$. Therefore, pro-inflammatory mediator release permitted by $\mathrm{PD}-1$ gene deficiency may be insufficient to account for the reduction in migratory capacity and/or the restoration of microbial phagocytic capacity.

Given the significantly reduced inflammatory response, we attempted to determine what if any evidence might exist that PD-1 interacts directly with integrins, such as CD11b, which might be involved in enhancing migration [34]. We carried out both immune staining with confocal assessment of relative cellular location of 


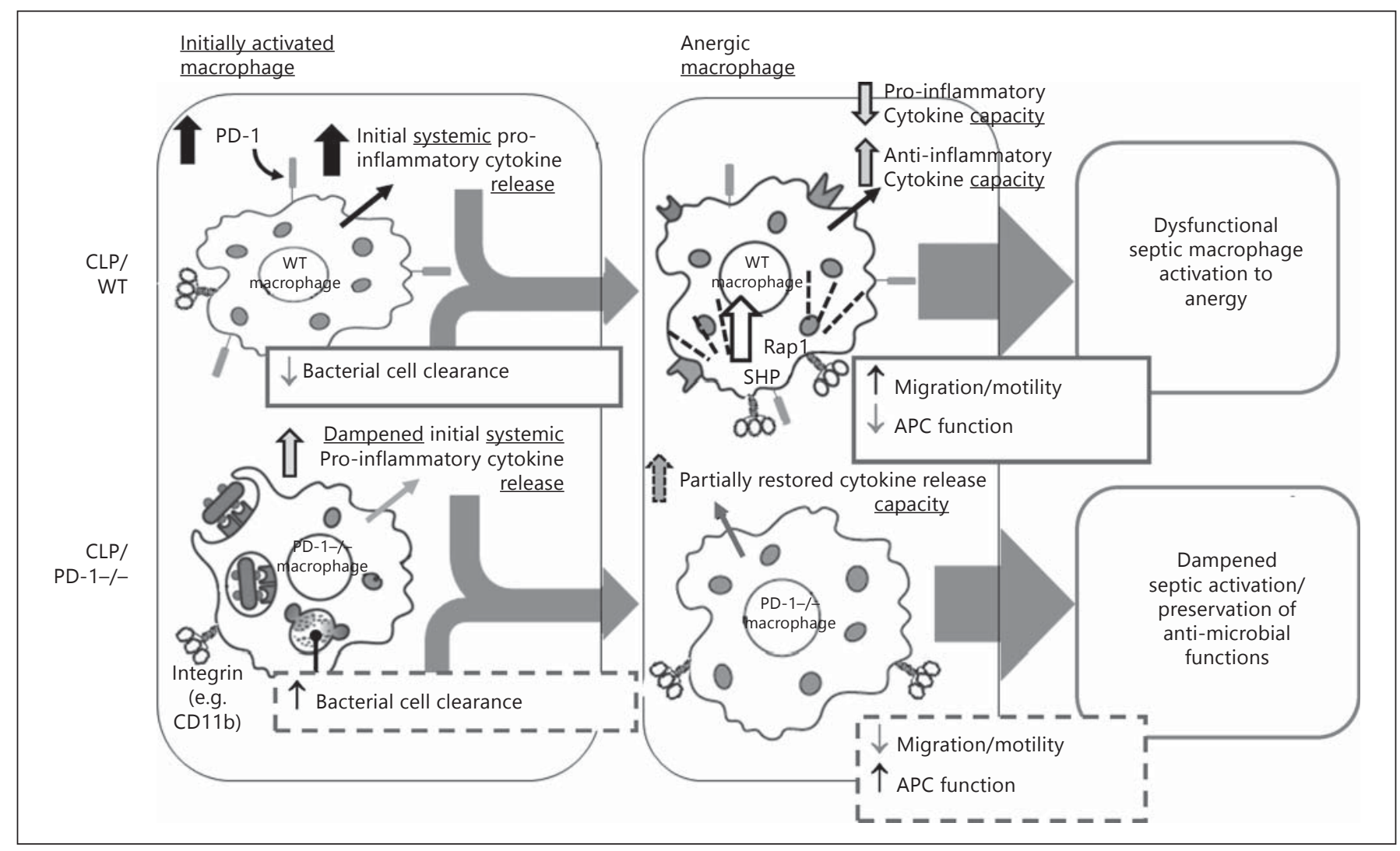

Fig. 9. A proposed model of how we believe the increase in septic WT mouse peritoneal macrophage expression of PD-1 (and the comparative effect of its absence in PD-1-/- mice) may affect the function of these leukocytes.

PD-1 to CD11b expression of Sham or CLP mouse peritoneal macrophages and immune precipitation using CD $11 b$ as bait for PD- 1 in these same cells. PD-1 appears to not only co-localize with $\mathrm{CD} 11 \mathrm{~b}$ as determined by Zstack analysis of confocal multiple color image analysis of the cell surface, but also by the ability to pull down PD-1 with $\mathrm{CD} 11 \mathrm{~b}$ during immune precipitation as measured by Western immunoblotting. There was also a more overt relationship in cells derived from CLP mice as these animals upregulated both the expression of PD- 1 and CD $11 \mathrm{~b}$ in response to septic challenge. To the best of our knowledge this is one of the few demonstrations of such co-localization of an ITIM receptor family member and an integrin [34]. Since CD11b has a role in a variety of leukocyte functions, such as migration and motility (which we have considered here), phagocytosis, as well as adhesionmediated activities such as immune synapse formation associated with antigen presentation and certain cytotoxic actions [39-41], interactions of CD11b with PD-1 and/ or other potentially cell-associated co-inhibitory molecules and/or their ligands might affect any of these pro- cesses and functions (see proposed model in fig. 9). However, this remains to be explored experimentally. In this respect, another example of an ITIM protein receptor interaction from Chen et al. [42] documented that Siglec G (in mice)/Siglec 10 (in humans) has the capacity to bind and interact with CD24, which subsequently permits the binding of various danger-associated molecular patterns by CD24. This binding altered the macrophage responsiveness, via TLR4, relative to its capacity to transduce an activating versus a non-activating signal when bound to danger-associated molecular patterns as opposed pathogen-associated molecular patterns. This group has also subsequently indicated that Siglec G, via its glycosylated extracellular facing side groups, can bind bacteria [43]; serving as a receptor involved in pathogen recognition related to bacterial clearance and phagocytosis. However, Siglec G's role in migration and/or its capacity to bind to other proteins associated with cell movement were not considered. In addition, we do not know the full spectrum of other protein:protein interactions that might be occurring with $\mathrm{PD}-1$. The significance of this $\mathrm{PD}-1: \mathrm{CD} 11 \mathrm{~b}$ in- 
teraction relative to migratory and/or phagocytic effects mediated by PD-1 is tempered somewhat by the observation that both the suppression of the increase in septic PD-1-/- mouse cell migratory capacity/cell spreading and the restoration of phagocytic capacity were independent of integrin ligand/opsonin binding. PD-1 ligation and subsequent downstream signaling events are the most likely mechanism by which such changes in cell function and phenotype are being mediated.

In conclusion, we have described a novel finding that PD- 1 contributes to macrophage migration during septic insult. Our data indicate that the role of PD-1 in macrophage migratory responsiveness during sepsis occurs in several different ways. Decreased migratory capacity, cell spreading and motility, due in part to changes in cytoskeletal $\alpha$-actinin and F-actin aggregation capabilities, decreased association of CD11b, and upstream downregulation of phosphatase and RAP1-dependent migration coalesce into macrophages that are less migratory than their WT counterparts. Additionally, PD-1-/- mouse cells have increased phagocytic ability. These observed changes provide further insight as to why $\mathrm{PD}-1-/-$ mice have a higher survival rate from CLP septic challenge. Increased phagocytosis would clearly be beneficial when trying to control a bacterial challenge. What exact benefit decreasing migration confers is not currently known. However, such changes could in turn allow a more stable T cell synapse interaction, which would improve overall immune responsiveness and aid in survival [44] (fig. 9). As macrophages are a bridge between innate and adaptive immune responses [12], improved communication between $\mathrm{T}$ cells and macrophages would increase an appropriate immune response to septic challenge. Additionally, decreased mobility coupled with increased phagocytic ability creates macrophages that stay at the infection site and clear more pathogens. Finally, not having a large influx of activated macrophages to the infection site may aid in survival as the immune response would be more directed/regulated, rather than massive uncontrolled inflammatory reaction causing large bystander tissue damage $[4,5]$. Downregulation of the PD-1 receptor during septic challenge as part of a treatment plan may be one way to aid in survival. Further work in these areas is ongoing.

\section{Acknowledgements}

This project was supported by NIH grants GM46354 and HL107149 (to A.A.), pre-doctoral undergraduate training support R25 HL088992 (to A.C.-R. and S.C.S.), 'W \& F Hewlett' Summer Research Collaboration Fellowship (to Y.S.K.), NRSA fellowship T32-GM65085 (to G.F.E.) and per-doctoral fellowship from the US Department of Education, GAANN-P200A100100 (to N.J.S.).

\section{References}

$\checkmark 1$ Angus DC, Linde-Zwirble WT, Lidicker J, Clermont G, Carcillo J, Pinsky MR: Epidemiology of severe sepsis in the United States: analysis of incidence, outcome, and associated costs of care. Crit Care Med 2001;29:13031310.

- 2 Deans KJ, Haley M, Natanson C, Eichacker PQ, Minneci PC: Novel therapies for sepsis: a review. J Trauma 2005;58:867-874.

-3 Rice TW, Bernard GR: Therapeutic interventions and targets for sepsis. Annu Rev Med 2005;56:225-248.

-4 Bone RC, Balk RA, Cerra FB, Dellinger RP, Fein AM, Knaus WA, et al: Definitions for sepsis and organ failure and guidelines for the use of innovative therapies in sepsis. Chest 1992;101:1644-1655.

-5 Levy MM, Fink MP, Marshall JC, Abraham E, Angus D, Cook D, et al: 2001 SCCM/ESICM/ ACCP/ATS/SIS International Sepsis Definitions Conference. Crit Care Med 2001;31: 1250-1256.

-6 Ward NS, Casserly B, Ayala A: The compensatory anti-inflammatory response (CARS) in critically ill patients. Clin Chest Med 2008;29: 617-625.
7 Hotchkiss RS, Karl IE: Medical progress: the pathophysiology and treatment of sepsis. $\mathrm{N}$ Engl J Med 2003;348:138-150.

-8 Xiao W, Mindrinos MN, Seok J, Cuschieri J, Cuenca AG, Gao H, et al: A genomic storm in critically injured humans. J Exp Med 2011; 208:2581-2590.

-9 Deitch EA: Rodent models of intra-abdominal infection. Shock 2006;24:19-23.

10 Rittirsch D, Huber-Lang MS, Flierl MA, Ward PA: Immunodesign of experimental sepsis by cecal ligation and puncture. Nat Protoc $2008 ; 4: 31-36$

11 Cinel I, Opal SM: Molecular biology of inflammation and sepsis. Crit Care Med 2009; 37:291-304.

12 Cavaillon J-M, Adib-Conquy M: Monocytes/ macrophages and sepsis. Crit Care Med 2005; 33:S506-S509.

13 Hume DA: Macrophages as APC and the dendritic cell myth. J Immunol 2008;181:58295835.

14 Martinez FO, Helming L, Gordon S: Alternative activation of macrophages: an immunologic functional perspective. Ann Rev Immunol 2011;27:451-483.
15 Cavaillon J-M, Adrie C, Fitting C, Adib-Conquy M: Reprogramming of circulatory cells in sepsis and SIRS. J Endotoxin Res 2005;11: 311-320.

16 Ayala A, Perrin MM, Chaudry IH: Defective macrophage antigen presentation following haemorrhage is associated with the loss of MHC class II (Ia) antigens. Immunology 1990;70:33-39.

17 Monneret G, Lepape A, Voirin N, Bohe J, Venet F, Debard AL, et al: Persisting low monocyte human leukocyte antigen-DR expression predicts mortality in septic shock. Intensive Care Med 2006;32:1175-1183.

18 Gallinaro RN, Naziri W, McMasters KM, Peyton JC, Cheadle WG: Alteration of mononuclear cell immune-associated antigen expression, interleukin- 1 expression, and antigen presentation during intra-abdominal infection. Shock 1994;1:130-134.

19 Huang X, Venet F, Wang YL, Lepape A, Yuan $Z$, Chen Y, et al: PD-1 expression by macrophages plays a pathologic role in altering microbial clearance and the innate inflammatory response to sepsis. Proc Natl Acad Sci USA 2009;106:6303-6308. 
20 Schneider H, Downey J, Smith A, Zinselmeyer BH, Rush C, Brewer JM, et al: Reversal of the TCR stop signal by CTLA-4. Science 2006; 313:1972-1975.

21 Riley JL: PD-1 signaling in primary T cells. Immunol Rev 2009;229:114-125.

-22 Schneider H, Valk E, Dias SR, Wei B, Rudd CE: CTLA-4 regulation of $T$ cell function via RAP-1-mediated adhesion. Adv Exp Med Biol 2006;584:115-126.

23 Ishida Y, Agata Y, Shibahara K, Honjo T: Induced expression of PD-1, a novel member of the immunoglobulin gene superfamily, upon programmed cell death. EMBO J 1992;11: 3887-3895.

-24 Ayala A, Perrin MM, Kisala JM, Ertel W, Chaudry IH: Polymicrobial sepsis selectively activates peritoneal but not alveolar macrophage to release inflammatory mediators (IL1, IL-6 and TNF). Circ Shock 1992;36:191-199.

25 National Research Council of the National Academies: Guide for the Care and Use of Laboratory Animals, ed 8. Washington, The National Academies Press, 2011.

26 Yang W, Arman CV, Im M, Alas A, Simaoka $\mathrm{M}$, Springer TA: A small molecule agonist of an integrin, $\alpha_{\mathrm{L}} \beta_{2}$. J Biol Chem 2006;281: 37904-37912.

-27 Elphick G, Sarangi P, Hyun Y-M, Hollenbaugh J, Ayala A, Biffl W, et al: Recombinant human activated protein $\mathrm{C}$ inhibits integrinmediated neutrophil migration. Blood 2009; 113:4078-4085.

28 Grutkoski PS, D’Amico R, Ayala A, Simms HH: TNF- $\alpha$ stimulated PMN suppress migration and bactericidal activity of PMN in a paracrine manner. Crit Care Med 2002;30:591-597.
29 McNeal SI, LeGolvan MP, Chung CS, Ayala A: The dual functions of receptor interacting protein 1 in Fas-induced hepatocyte death during sepsis. Shock 2011;35:499-505.

30 Chung CS, Chen YP, Grutkoski PS, Doughty LA, Ayala A: SOCS-1 is a central mediator of steroid-increased thymocyte apoptosis and decreased survival following sepsis. Apoptosis 2007; 12:1143-1153.

31 Owada T, Watanabe N, Oki M, Oya Y, Saito Y, Saito T, et al: Activation-induced accumulation of $\mathrm{B}$ and $\mathrm{T}$ lymphocyte attenuator at the immunological synapse in CD4+ T cells. J Leukoc Biol 2010;87:425-432.

32 Schneider H, Mandelbrot DA, Greenwald RJ, Ng F, Lechler R, Sharpe AH, et al: CTLA-4 (CD152) differentially regulates mitogen-activated protein kinases (extracellular signalregulated kinase and c-Jun $\mathrm{N}$-terminal kinase) in $\mathrm{CD} 4+\mathrm{T}$ cells from receptor/ligand-deficient mice. J Immunol 2002;169:3475-3479.

33 Dillion TJ, Carey KD, Wetzel SA, Parker DC, Stork JS: Regulation of the small GTPase Rap1 and extracellular signal-regulated kinases by the costimulatory molecule CTLA-4. Mol Cell Biol 2005;25:4117-4128.

34 Schneider H, Valk E, Dias SR, Wei B, Rudd CE: CTLA-4 up-regulation of lymphocyte associated antigen 1 adhesion and clustering as an alternate basis for coreceptor function. Proc Natl Acad Sci USA 2005; 102:1286112866.

- 35 Monaghan SF, Thakkar RK, Heffernan DS, Tran HL, Huang X, Chung CS, et al: Mechanisms of indirect acute lung injury: a novel role for the co-inhibitory receptor, programmed death-1 (PD-1). Ann Surg 2012; 255:158-164.
36 Brahmamdam P, Inoue S, Unsinger J, Chang KC, McDunn JE, Hotchkiss RS: Blocking PD-1 inhibits lymphocyte apoptosis during sepsis. J Leukoc Biol 2010;88:233-240.

37 Zhang Y, Zhou Y, Lou J, Li J, Bo L, Zhu K, et al: PD-L1 blockade improves survival in experimental sepsis by inhibiting lymphocyte apoptosis and reversing monocyte dysfunction. Crit Care 2010;14:R220.

38 Guignant C, Lepape A, Huang X, Kherouf H, Denis L, Poitevin F, et al: Programmed death-1 levels correlate with increased mortality, noscomial infection and immune dysfunction in septic shock patients. Crit Care 2011;15:R99.

39 Arnaout MA: Structure and function of the leukocyte adhesion molecules CD11/CD18. Blood 1990;75:1037-1050.

40 Ross GD, Vetvicka V: CR3 (CD11b, CD18): a phagocyte and NK cell membrane receptor with multiple ligand specificities and functions. Clin Exp Immunol 1993;92:181-184.

41 Davis DM, Dustin ML: What is the importance of the immunological synapse? Trends Immunol 2004;25:323-327.

42 Chen GY, Tang J, Zheng P, Liu Y: CD24 and siglec- 10 selectively repress tissue damage-induced immune responses. Science 2009;323: 1722-1725.

43 Chen GY, Chen X, King S, Cavassani KA, Cheng J, Zheng X, et al: Amelioration of sepsis by inhibiting sialidase-mediated disruption of the CD24-SiglecG interaction. Nat Biotechnol 2011;29:428-435.

44 Huppa JB, Davis MM: T-cell-antigen recognition and the immunological synapse. Nat Rev Immunol 2003;3:973-983. 